\title{
ELECTROENCEPHALOGRAPHIC AND \\ BEHAVIORAL AROUSAL EFFECTS \\ OF SMALL DOSES OF NICOTINE: \\ A NEUROPSYCHOPHARMACOLOGICAL STUDY*
}

\author{
Edward F. Domino \\ Department of Pharmacology \\ The University of Michigan \\ Ann Arbor, Michigan \\ INTRODUCTION
}

Nicotine is a well known "nicotonic" ( $n$ ) cholinergic agonist with widespread effects upon the autonomic, respiratory, and neuromuscular systems. By virtue of its actions on a variety of peripheral nerve receptors, it causes marked changes in heart rate, blood pressure, and respiration. So prominent are the peripheral actions of small doses of nicotine that its effects upon the central nervous system have been neglected or unappreciated by most investigators interested in the pharmacology of tobacco smoking. In most studies of these effects, doses large enough to be toxic have been used, because the drug is a valuable pharmacological tool for studying cholinergic mechanisms. Small doses stimulate, and large doses block $n$ cholinergic synaptic transmission. Many of the neuropharmacological and behavioral studies with nicotine, although of academic interest, are clearly unrelated to tobacco smoking (Silvette et al., 1962).

Our own interest in nicotine is motivated in part by the fact that it is one of the few cholinergic agonists that can easily penetrate the blood-brain barrier. At $\mathrm{pH} 7.4$ and a temperature of $37^{\circ} \mathrm{C}$, the pyrrolidine nitrogen has been calculated to be about $69 \%$ ionized (Domino, 1965b). The $31 \%$ of nicotine molecules that are not ionized can readily penetrate the blood-brain barrier. Although the nonionized molecules are the ones that penetrate into various tissues, the charged form is responsible for the pharmacological effects (Barlow \& Hamilton, 1962; Barlow, 1965). The ability of nicotine to penetrate into the central nervous system has been demonstrated dramatically in both the mouse and the cat by Schmiterlöw and Hansson (1965), using autoradiographic techniques. Even though the compound can penetrate readily into the brain and spinal cord, attempts to determine its direct actions upon the central nervous system are fraught with error because of its widespread peripheral autonomic effects. Because relatively small doses of nicotine, on the order of $5-40 \mu \mathrm{g} / \mathrm{kg}$, produce dramatic cardiovascular effects in unanesthetized animals or man, we have tended to use minimal doses in most of our studies.

*Supported in part by grants from the Council for Tobacco Research, USA and B-01311, USPHS. 
In this symposium, I will attempt to review and summarize the results obtained in my laboratory to date. This research is a collaborative effort involving my former graduate students and associates of the past six years, including Drs. Dren, Knapp, Varma, Villarreal, and Yamamoto. Some of the data have already been published; other portions are being prepared for publication in more detail in the near future. A summary of all the data and a synthesis of the results are presented herein.

So far, we can say something about the actions of small doses of nicotine upon the central nervous system and about central cholinergic mechanisms. Their relationship to tobacco smoking is still unknown, but any theory of the cause of tobacco habituation must take into account the rather clear-cut central actions of very small doses of nicotine. We have used a neuro- and psychopharmacologic approach to determine the central actions of nicotine. Since nicotine releases catecholamines, serotonin, and vasopressin, these compounds have been studied as well. The effects of nicotine and related cholinergic agonists were determined in acute and chronic experiments. The actions of nicotine upon gross and conditioned avoidance behavior were determined to provide a behavioral correlate of the effects upon the central nervous system.

\section{Effects of Nicotine upon the EEGs of Animals with Acute. Transection of the Brainstem}

\section{EEG Activation in Midpontine Rabbits, Cats, Dogs, and High-Pontine Monkeys}

It is well known that large doses of nicotine, by direct action upon the brain, produce a tremor which is usually followed by muscular convulsions (Silvette et al., 1962). Grand mal convulsions can be produced in most mammals. In our experience, rodents are especially easy to study in this regard. A large variety of anesthetic, adrenergic blocking, antihistaminic, and cholinergic blocking drugs have been used as nicotinic antagonists. It is of interest that the convulsant actions of nicotine can be antagonized readily by $n$ ganglionic blocking drugs which penetrate the central nervous system, especially mecamylamine (Stone et al., 1956). Before the development of typical grand mal convulsions, an initial period of EEG desynchronization can usually be seen, particularly if the prior EEG pattern shows some slowing. Even if the drug is given in subconvulsant doses, EEG desynchronization can occur (Longo et al., 1954; Silvestrini, 1958; Stümpf, 1959; Dunlop et al., 1960; Floris et al., 1962; Silvette et al., 1962). Floris et al. (1962) reported that large doses of nicotine produce EEG desynchronization and seizures in mesencephalic-transected rabbits. These investigators suggested that the origin of the seizure discharge was in the hippocampus.

The site and mechanism of the action of nicotine in producing EEG activation was not known, because epinephrine and other substances released 
peripherally by nicotine might account for the EEG activation observed. Therefore, we felt that the first problem was to show that the EEG activation induced by nicotine was due to direct action upon the brain (Knapp \& Domino, 1962). Since most drugs that produce EEG activation have no significant effect in animals showing a baseline of EEG activation, it was thought to be necessary to use a preparation which had stable slow waves and spindles. It was decided to use a modification of Bremer's (see 1953 review) prepontine brainstem transection (classical cerveau isolé), which results in EEG phenomena indistinguishable from those recorded during natural sleep or barbiturate hypnosis. Such a preparation is capable of showing EEG activation with small doses (1-4 $\mu \mathrm{g} / \mathrm{kg}$ ) of epinephrine given intravenously (Bonvallet et al., 1954).

Knapp developed an ingenious method for performing brainstem transections by using a series of specially designed spatulas. Typical high-voltage slow waves and spindle bursts can be readily obtained in an intercollicular, midpontine, pretrigeminal brainstem transection in animals prepared acutely under diethyl ether anesthesia, local lidocaine, immobilization with decamethonium, and artificial ventilation. Such preparations show stable EEG slow waves and spindles in the rabbit, cat, and dog. For example, in the dog, the most prominent change is the appearance of $10-14 \mathrm{cps}$ spindle bursts at a mean frequency \pm standard deviation (SD) of $13.1 \pm 3.0$ per minute. Between the EEG spindles, there occasionally appear slow waves and bursts of low-voltage, fast-frequency activity. However, no EEG activation is produced by any of a variety of afferent stimuli. In our laboratory, such preparations were stable for periods up to 18 hours. Intracranial bleeding and cerebral edema proved to be the main problems in maintaining EEG activity in brainstem-transected animals.

Several species were studied, including rabbits, cats, dogs, and monkeys. Electrical activity was recorded from the sensorimotor area, using both monopolar and bipolar recordings. The elevated skin of the scalp served as the reference area for the monopolar recordings. Before any drugs were tested, at least three hours were allowed for elimination of the diethyl ether anesthesia used in preparing the animals.

Within one minute after the intravenous injection of $10-20 \mu \mathrm{g} / \mathrm{kg}$ of nicotine, EEG activation occurred in all four species. This is illustrated for the rabbit, cat, and dog in FIGURE 1. Usually within four minutes, spindle bursts reappeared. After six minutes, spindle bursts were the dominant feature of the recordings; often they were more prominent than before the nicotine injection.

The actions of epinephrine and serotonin, in contrast, showed considerable species variation. For example, epinephrine, in intravenous doses as large as $8 \mu \mathrm{g} / \mathrm{kg}$, did not produce EEG activation in the midpontine dog (see FIGURE 2) or the high-pontine monkey. Serotonin in intravenous doses of $30 \mu \mathrm{g} / \mathrm{kg}$ produced EEG activation in the midpontine rabbit and cat but 


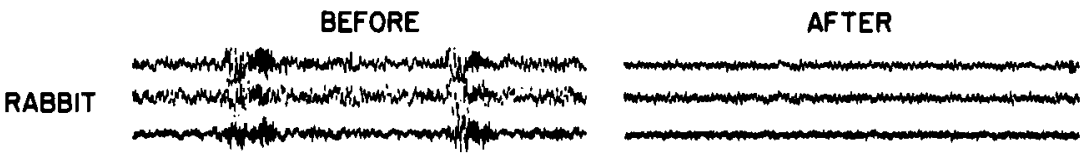

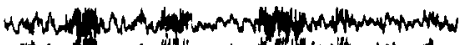

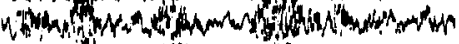
rin

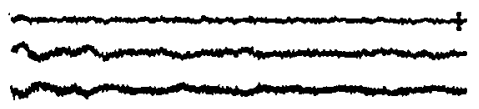

DOG
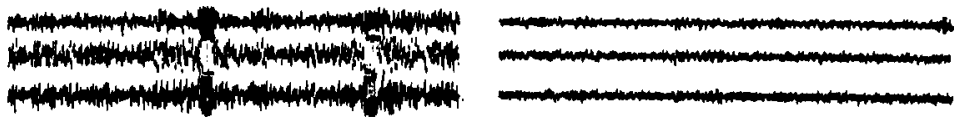

rac.

FIGURE 1. Effect of Nicotine upon the EEG of the Midpontine Rabbit, Cat, and Dog. Intravenous injection of $20 \mu \mathrm{g} / \mathrm{kg}$ of nicotine produced EEG activation within one minute after injection in all species tested. Channels 1,2 , and 3 are respectively monopolar right somatosensory area, monopolar left somatosensory area, and bipolar right to left somatosensory areas. Vertical calibration bars, 100 microvolts.

BEFORE

RABBT

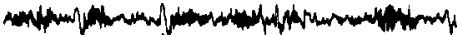

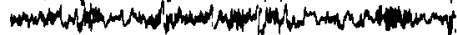

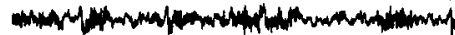

AFTER

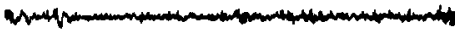

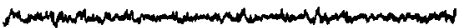

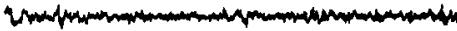

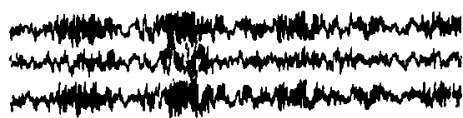

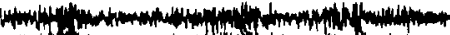
DOG

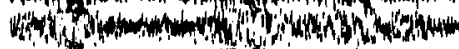

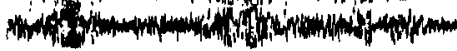
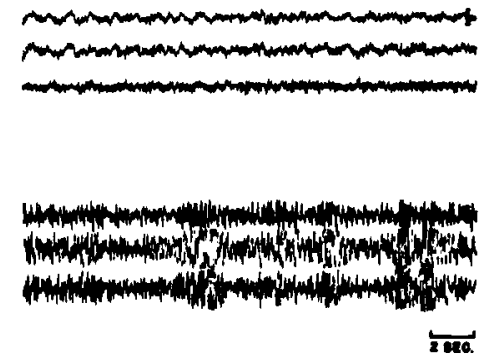

FIGURE 2. The Effect of Epinephrine upon the EEG of the Midpontine Rabbit, Cat, and Dog. Intravenous injection of up to $8 \mu \mathrm{g} / \mathrm{kg}$ of epinephrine did not produce EEG activation in the midpontine dog but did in the rabbit and cat within 1 minute. Channels and calibration as in FIGURE 1. 
not in the midpontine dog or high-pontine monkey. These results suggested that the EEG activation induced by nicotine was not due to the release from peripheral structures of epinephrine or serotonin which would then act upon the brain of the dog and monkey.

\section{Additional Evidence for a Direct Action of Nicotine upon the Brain}

To show that the action of nicotine upon the EEG of the midpontine dog was due to a direct effect upon the brain, a series of dogs was completely deafferented by pretrigeminal transection, section of the optic nerves, bilateral coagulation of the oculomotor nerves, and topical lidocaine anesthesia of the olfactory mucosa. In these animals, nicotine also produced EEG activation of a duration similar to that in other midpontine-transected preparations with intact cranial nerves I, II, and III.

Further evidence that nicotine induces EEG activation by a direct effect upon the central nervous system was provided by the dissociation between nicotine-induced blood pressure changes and EEG activation after the administration of $n$ cholinergic ganglionic blocking agents. The administration of hexamethonium $(5 \mathrm{mg} / \mathrm{kg})$ or trimethidinium methosulfate $(4 \mathrm{mg} / \mathrm{kg})$ prevented the cardiovascular changes induced by nicotine, but not EEG activation. In contrast, the secondary amine, mecamylamine, also an $n$ cholinergic ganglionic antagonist, blocked the cardiovascular as well as the EEG activation induced by $20 \mu \mathrm{g} / \mathrm{kg}$ of nicotine administered intravenously.

Another line of evidence that the EEG activation induced by nicotine is not mediated by the release of peripheral stores of catecholamines or by changes in cerebral blood flow was obtained with the quaternary $n$ cholinergic ganglionic stimulants dimethylphenylpiperazinium (DMPP) and nicotine monomethiodide. DMPP, in intravenous doses of 5-10 $\mu \mathrm{g} / \mathrm{kg}$, caused large but variable increases in blood pressure. Though it produced marked peripheral cardiovascular changes, DMPP did not alter the EEG patterns in midpontine-transected dogs, nor did nicotine monomethiodide in doses of $20-40 \mu \mathrm{g} / \mathrm{kg}$. The effects of DMPP and of nicotine are compared in FIGURE 3. Of considerable interest is the fact that a second dose of nicotine, given 10 minutes after the first dose, shows tachyphylaxis in producing EEG activation. As shown in TABLE 1, if nicotine is given at intervals of less than 15 minutes, tachyphylaxis to the induction of EEG activation is complete. It is necessary to wait at least 30 minutes to get reproducible nicotine EEG activation.

To rule out the possibility that vasopressin release might account for nicotine-induced EEG activation, vasopressin (Pitressin) was given in large doses, $200 \mathrm{mU} / \mathrm{kg}$. Although blood pressure changed markedly, there was no EEG activation in the midpontine-transected dog. An interesting interaction between vasopressin and nicotine was observed which needs to be followed further. When small doses of nicotine were administered after the 
BEFORE

AFTER

OMPP

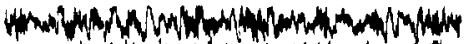 W

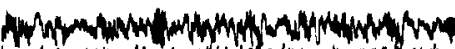

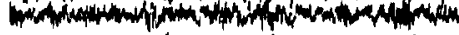

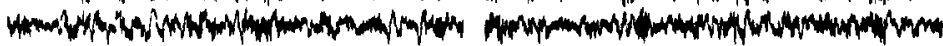

NICOTINE

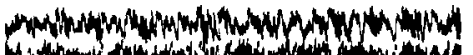

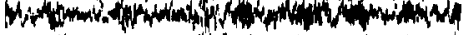

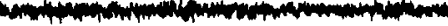

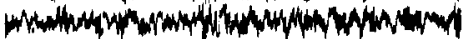

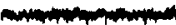

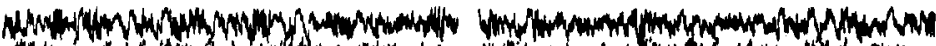

NICOTINE

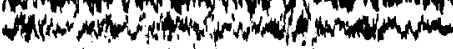

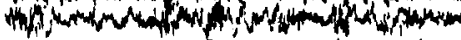

(ten min)

4.

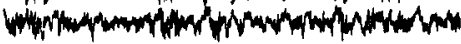

Tute

FIGURE 3. Specificity of Nicotine-induced EEG Activation in the Midpontine Dog. The illustration emphasizes two important points: (1) In contract to nicotine, DMPP in doses of 5-10 $\mathrm{\mu g} / \mathrm{kg}$ does not cause EEG activation. (2) A second dose of nicotine 10 minutes after the first dose shows marked tachyphylaxis has occurred. Channels and calibration as in FIGURE 1.

TABLE 1

TIME INTERVAL BETWEEN INJECTIONS FOR TACHYPHYLAXIS TO EEG ACTIVATION INDUCED BY NICOTINE

\begin{tabular}{l|c|c}
\hline $\begin{array}{c}\text { Minutes } \\
\text { between } \\
\text { injections }\end{array}$ & $\begin{array}{c}\text { Number } \\
\text { of } \\
\text { observations }\end{array}$ & $\begin{array}{c}\text { Percent EEG } \\
\text { activations } \\
\text { to second dose }\end{array}$ \\
\hline Less than 15 & 6 & 0 \\
$15-29$ & 12 & 66 \\
30 or more & 29 & 100 \\
\hline
\end{tabular}

injection of vasopressin, EEG activation did not occur. Intervals of at least 30 minutes between injections of nicotine (to prevent possible interaction with the previous dose of nicotine) were necessary before EEG activation was elicited. Large doses of vasopressin then, at least initially, tended to antagonize activation of the EEG by nicotine.

Reserpine pretreatment, in intramuscular doses of $0.5 \mathrm{mg} / \mathrm{kg}$, also had no significant effect upon EEG activation induced by nicotine, although the amounts of brainstem amines were markedly reduced (see FIGURE 4). 


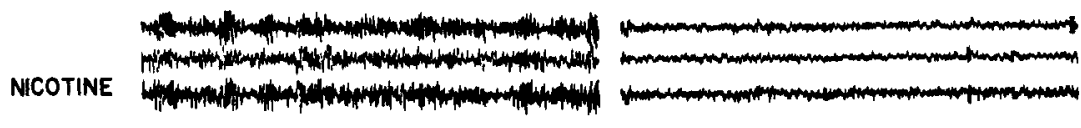

$\begin{array}{cccc} & \text { DOG BRANSTEM AMINES } & \\ \text { 24 HOURS POST } & \text { O.5MG./KG. RESERPINE } & \\ \text { DOG } & \text { NOREPINEPHRINE } & \text { EPINEPHRINE } & \text { SEROTONIN } \\ 1 & 0.003 & 0.000 & 0.000 \\ 2 & 0.003 & 0.000 & 0.000 \\ 3 & 0.006 & 0.004 & 0.000 \\ 4 & 0.003 & 0.000 & \\ 5 & 0.006 & 0.001 & \\ 6 & 0.006 & 0.000 & 0.410 \\ 7 \text { control } & 0.170 & 0.012 & \end{array}$

FIGURE 4. Nicotine-induced EEG Activation in the Reserpinized Midpontine Dog. The effects of intravenous nicotine $(20 \mu \mathrm{g} / \mathrm{kg})$ were not significantly altered in animals given $0.5 \mathrm{mg} / \mathrm{kg}$ of reserpine intramuscularly 24 hours previously. Note that the brainstem amines are markedly reduced at this time. Channels and calibration as in FIGURE 1.

\section{Site of Action of Nicotine in Inducing EEG Activation}

To identify further the precise site or circuit involved in the activation of the EEG by nicotine, a series of brainstem transections was performed in the dog. The quaternary ganglionic blocking agent trimethidinium was given before the nicotine injections to prevent the considerable bleeding that occurs due to the marked cardiovascular effects of nicotine. In midpontine dogs responsive to nicotine, a higher level of transection, at a prepontine level, blocked the EEG activation of nicotine. This was not true of the cat, however; apparently there is a species difference. A dose of $0.25 \mathrm{mg} / \mathrm{kg}$ of $d$-amphetamine produced EEG activation in prepontine dogs and cats. It would appear that the neuronal circuits necessary for $d$-amphetamine-induced EEG activation in the dog are at a more rostral level than those sensitive to nicotine. Furthermore, the EEG activation induced by $d$-amphetamine lasted considerably longer.

In isolated in vivo reticular slab experiments in the dog, it was possible to show that nicotine in doses of $20 \mu \mathrm{g} / \mathrm{kg}$ produced desynchronization somewhat similar to that in the neocortex. This indicates that nicotine can exert a desynchronizing effect upon EEG activity in an isolated portion of reticular formation. These experiments have led us to conclude that one site of action of nicotine is in some neurons of the pontine reticular formation. Of course, these experiments do not rule out any actions of nicotine upon other levels of the cerebrospinal axis. In fact, some of our own data from cats 
suggest that the hippocampal system is another important site of action of small doses of nicotine.

\section{Differential Receptors for EEG Activation by $n$ and $m$ Cholinergic} Agonists in the Intercollicular-High-Pontine Cat

Since nicotine is predominantly an $n$ cholinergic agonist, its interaction with predominantly "muscarinic" $(m)$ cholinergic agonists, such as arecoline, was of interest. As described previously, the EEG activation induced by nicotine shows rapid tachyphylaxis. This phenomenon has been used to dissociate the types of cholinergic receptors involved in EEG desynchronization (Villarreal \& Domino, 1964). Intercollicular, high-pontine brainstemtransected cats were prepared under halothane-oxygen anesthesia and maintained with artificial respiration. EEG desynchronization was induced with intravenous arecoline and/or nicotine. The peripheral autonomic effects of these agents were blocked with atropine methylnitrate $(0.25 \mathrm{mg} / \mathrm{kg})$ and trimethidinium methosulfate $(1.0 \mathrm{mg} / \mathrm{kg})$.

Repeated doses of nicotine, in multiples of $40.5 \mu \mathrm{g} / \mathrm{kg}$, at one-to-10-minute intervals, showed rapid tachyphylaxis for EEG activation, as FIGURE 5

Bofore

After

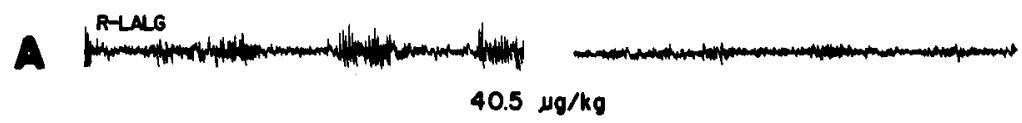

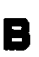
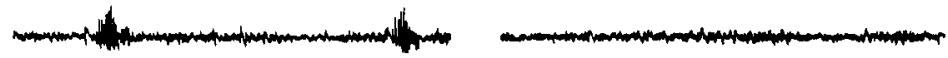

$81 \mathrm{ug} / \mathrm{kg}$
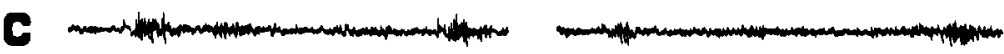

$8 / \mu g / k g$

a
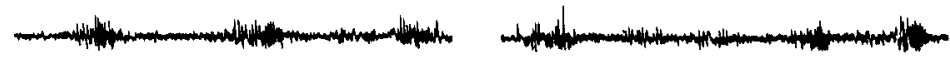

$162 \mu \mathrm{gg} / \mathrm{kg}$
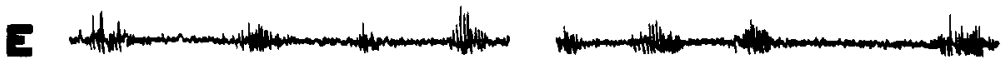

$324 \mu \mathrm{g} / \mathrm{kg}$
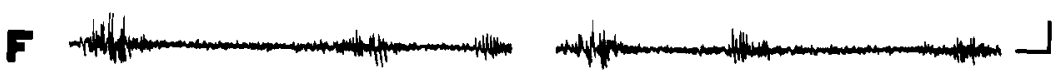

$648 \mu \mathrm{gkg}$

FIGURE 5. Tachyphylaxis to the EEG Effects of Nicotine in the Brainstemtransected Cat. The animal was prepared under halothane anesthesia with an intercollicular, high pontine transection. After recovery from anesthesia, the EEG was recorded bipolarly from the right to left anterior lateral gyrus (R-LALG). In panel $A$ is illustrated the EEG before and one minute after $40.5 \mu \mathrm{g} / \mathrm{kg}$ of nicotine intravenously. As the dose of nicotine was progressively increased, marked tachyphylaxis to nicotine was observed, as shown in panels B through $F$. The vertical calibration bar represents 100 microvolts, and the horizontal bar represents one second. 
shows. Total cumulative doses of nicotine as large as $3 \mathrm{mg} / \mathrm{kg}$ in less than one hour were usually given. It can be seen that after an initial dose of $40.5 \mu \mathrm{g} / \mathrm{kg}$ of nicotine, EEG activation was observed; as the dose was repeated and increased, marked tachyphylaxis to nicotine occurred. After the administration of a total of $2 \mathrm{mg} / \mathrm{kg}$ of nicotine, complete tachyphylaxis to nicotine was observed. Under these conditions, the administration of $77.5 \mu \mathrm{g} / \mathrm{kg}$ of arecoline, which produced EEG activation before the tachyphylaxis to nicotine, retained essentially the same EEG effects (see FIGURE 6). Nicotine
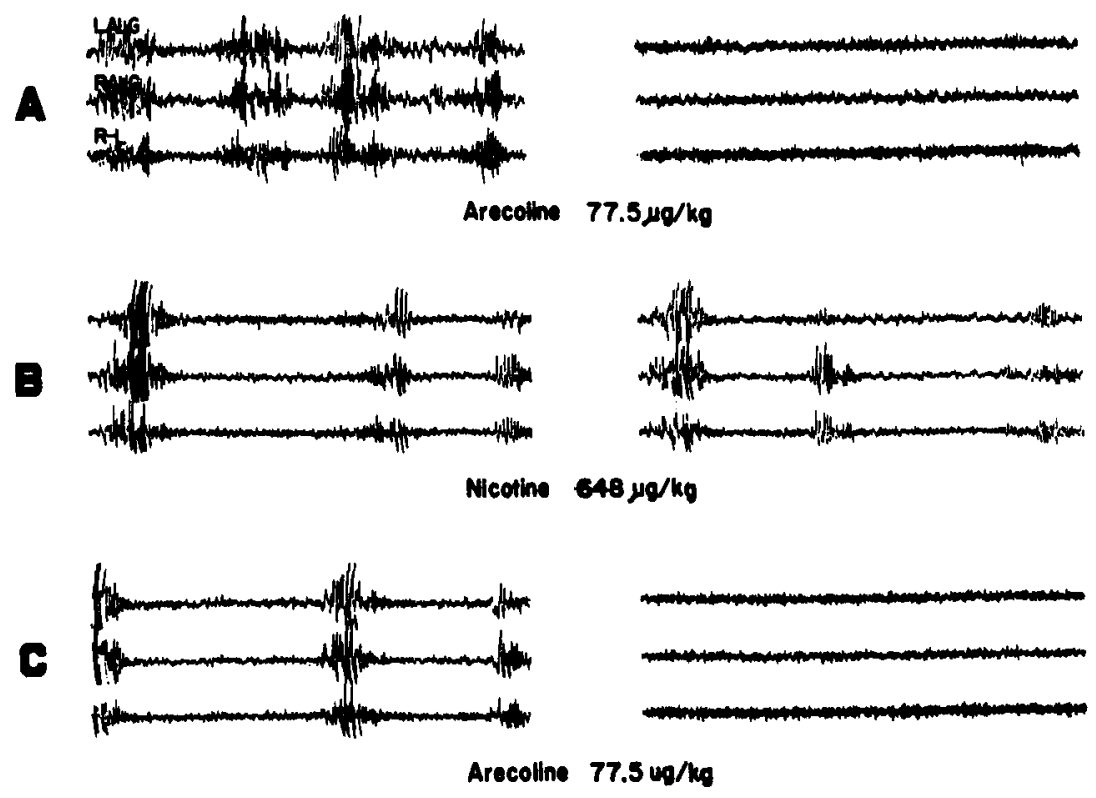

FIGURE 6. Effects of Arecoline During Nicotine-Induced EEG Tachyphylaxis in the Brainstem-transected Cat. The EEG was recorded both monopolarly and bipolarly in an intercollicular, high pontine-transected cat. Panel A shows the control EEG pattern before and after $77.5 \mu \mathrm{g} / \mathrm{kg}$ of arecoline intravenously. Panel B shows the EEG pattern after nicotine tachyphylaxis, in which $648 \mu \mathrm{g} / \mathrm{kg}$ of nicotine intravenously did not cause EEG activation. Subsequently, as shown in Panel C, arecoline in the same dose as in Panel A caused EEG activation. Symbols and calibration as in FIGURE 5.

produced EEG activation in somewhat smaller doses than arecoline, but the latter compound caused a more marked, dramatic, and prolonged activation.

Another line of evidence which supports the hypothesis that $m$ cholinergic receptors are independent in EEG activation was obtained with mecamylamine. As described above, this $n$ cholinergic ganglionic antagonist can penetrate more readily through the blood-brain barrier. Mecamylamine, in doses of $0.5 \mathrm{mg} / \mathrm{kg}$, blocked the EEG effects of $40.5 \mu \mathrm{g} / \mathrm{kg}$ of nicotine (see FIGURE 7), but even large doses $(5.0 \mathrm{mg} / \mathrm{kg})$ failed to block the EEG effects of arecoline. Whereas mecamylamine selectively blocked the activation induced 


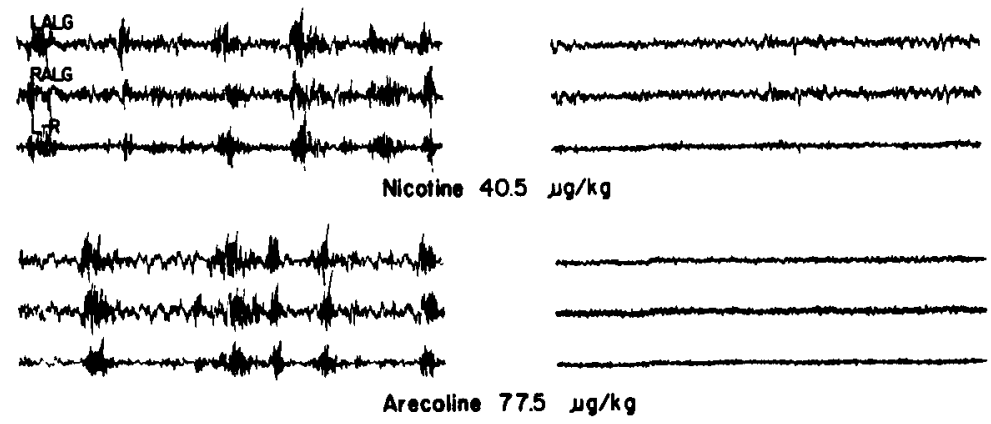

\section{MECAMYLAMINE $0.5 \mathrm{mg} / \mathrm{kg}$}
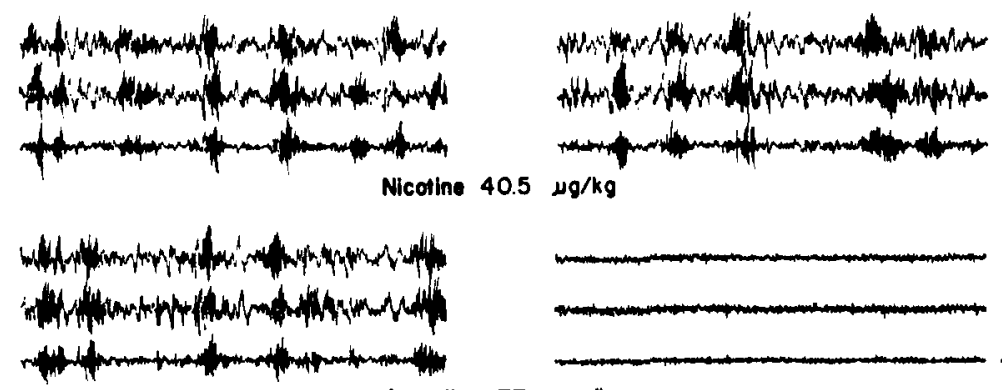

Arecoling $77.5 \mu g / \mathrm{kg}$

FIGURE 7. Specificity of Mecamylamine in Blocking the EEG Effects of Nicotine but not of Arecoline in the Brainstem-transected Cat. In the intercollicular, high pontine-transected cat, both nicotine and arecoline produced EEG activation. After mecamylamine $(0.5 \mathrm{mg} / \mathrm{kg}$ intravenously), EEG activation by nicotine was blocked, but that of arecoline was still evident. Symbols and calibration as in FIGURE 5.

by nicotine but not that of arecoline, large doses $(1.0 \mathrm{mg} / \mathrm{kg})$ of atropine blocked both.

The hypothesis that $n$ cholinergic receptors are independent of each other, but do depend upon $m$ cholinergic receptors for EEG activation, is further supported by another set of experiments. It has been shown (Dren \& Domino, 1965) that hemicholinium, when injected into the lateral ventricle of the rat or the dog, produces marked EEG changes. Since hemicholinium competes with the uptake of choline and reduces brain acetylcholine content, it has been concluded that the drug acts through interference with central cholinergic mechanisms (Domino et al., 1965). Large intraventricular doses $(1.25 \mathrm{mg} / \mathrm{kg}$ ) of hemicholinium, given to the intact, locally anesthetized, paralyzed, and artificially respired dog, produce marked neocortical as well as limbic EEG changes. Slow wave and spikelike EEG phenomena induced by hemicholinium can be reversed by the administration of $40 \mu \mathrm{g} / \mathrm{kg}$ of arecoline, but cannot be well antagonized by nicotine in comparable intravenous doses (see FIGURE 8). Choline, physostigmine, and pilocarpine also antagonize the EEG changes 

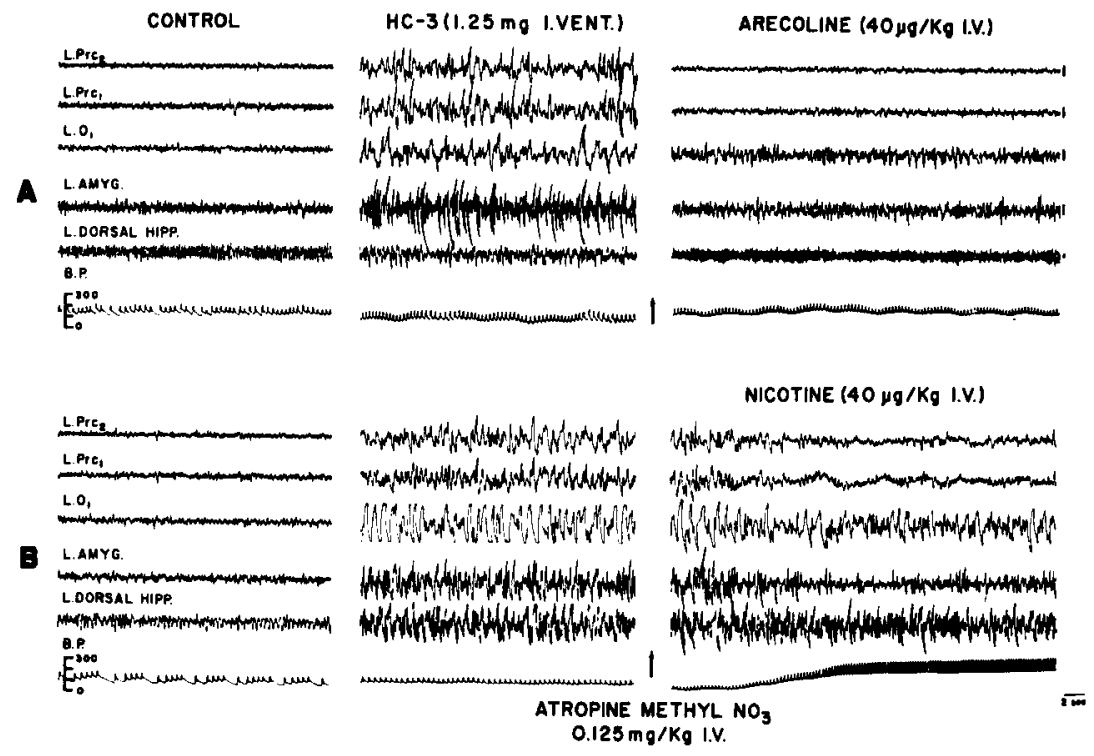

FIGURE 8. Differential EEG Effects of Intravenous Arecoline and Nicotine after Intraventricular Hemicholinium in the Dog. Hemicholinium (HC-3) was given in a total dose of $1.25 \mathrm{mg}$ into the lateral ventricle of an intact, decamethonium-paralyzed, locally anesthetized dog on artificial ventilation. The control EEG was recorded monopolarly from neocortical and limbic brain areas. Arterial blood pressure was recorded as well. Panels $A$ and $B$ illustrate the differential effects of arecoline and nicotine given 2-4 hours after HC-3. HC-3 produced marked EEG changes in both neocortical and limbic structures. These changes were reversed by arecoline in a dose of $40 \mu \mathrm{g} / \mathrm{kg}$ given intravenously. On the other hand, nicotine, in the same dose, did not produce nearly as dramatic an EEG reversal in the neocortex and produced none in the hippocampus. Methylatropine was given in a dose of $0.125 \mathrm{mg} / \mathrm{kg}$ intravenously before arecoline to reduce its peripheral cardiovascular effects. Symbols: L.Prc 2 -motor cortex; L.Prc 1 -sensory cortex; L. $0_{1}$-left occipital cortex; L.AMYG-left basolateral amygdala; L. Dorsal Hipp-left dorsal hippocampus. All EEG recordings were monopolar, referred to the nasion. Femoral arterial blood pressure was recorded on channel 6 and calibrated in $\mathrm{mm}$ HG. Vertical bars for voltage calibration, 100 microvolts.

induced by hemicholinium, but $d$-amphetamine does not. These experiments indicate that brain structures contain at least two types of cholinergic receptors capable of inducing EEG desynchronization. The $n$ cholinergic receptor mechanisms appear to be less effective than the $m$ cholinergic receptor mechanisms for inducing EEG activation in both the cat and the dog.

\section{EfFects of Nicotine in Cats with \\ Chronically Indwelling Brain Electrodes}

Acute EEG studies provide little information about the behavioral consequences of nicotine. In animals with intact brains, EEG desynchronization recorded from neocortical structures can occur in at least two different behavioral states: (a) wakefulness, and (b) the activated, "paradoxical," or 
fast-wave phase of sleep (Dement \& Kleitman, 1957; Dement, 1958; Yamamoto, 1959; Jouvet, 1961; Yamamoto \& Kido, 1962. To ascertain whether the EEG desynchronizing actions of nicotine are related to behavioral arousal or to the fast-wave phase of sleep, it was necessary to study the effects of nicotine upon intact animals with chronically implanted brain electrodes. This we have done using cats (Yamamoto \& Domino, 1965; Domino \& Yamamoto, 1965). Various pharmacological pretreatments were given using the strategy and knowledge obtained from the acute experiments, to determine whether the actions of nicotine observed were due primarily to peripheral or central components.

\section{Effects of Small Doses of Nicotine upon the EEG and Behavioral Stages of Sleep}

Cats were selected because they readily sleep during the daytime and show a fairly regular sleep-wake cycle. The circadian sleep and waking patterns of the laboratory cat have recently been described in detail by Sterman et al. (1965). Our animals were routinely studied in the daytime. The study was performed in 15 cats with chronically indwelling electrodes in the somatosensory cortex, the hippocampus, the amygdala, the posterior hypothalamus, and the midbrain reticular formation. The animals were prepared with indwelling brain electrodes by conventional stereotoxic techniques. For intravenous injection, Silastic tubing was used for an indwelling cannula in the jugular vein. All surgery was performed under pentobarbital anesthesia. Two weeks of convalescence were allowed before the experimental studies. When the animals recovered fully from the operative procedures, they were placed in a warm, soundproof, insulated box which had a one-way window for observation. The natural sleep-awake cycle of each animal was then recorded throughout the experimental day. All medications were given in an incomplete Latin square design.

Intravenous infusions of warmed physiological saline, in doses of 1.5 to $2.0 \mathrm{ml}$, given over a one-minute period, had no significant EEG or behavioral consequences in cats which were in natural slow-wave (deep) sleep, as evidenced behaviorally and by the EEG. In contrast, nicotine in doses of 5-10 $\mu \mathrm{g} / \mathrm{kg}$ produced three distinct EEG and behavioral phenomena. The first was a brief period (approximately three minutes) of neocortical desynchronization and hippocampal theta activity, accompanied by behavioral wakeup from natural slow-wave sleep. Then the animals lapsed into slow-wave sleep again, as evidenced behaviorally and by the EEG; often they slept more deeply than before the nicotine injection. After about 15-25 minutes, an increased incidence of activated sleep was observed. These EEG effects of nicotine are illustrated in FIGURE 9. The changes in EEG, electrocardiogram (EKG), and respiration can be plotted over a period of time in the form of a line graph to illustrate more clearly the phenomena observed (see FIGURE 10). 


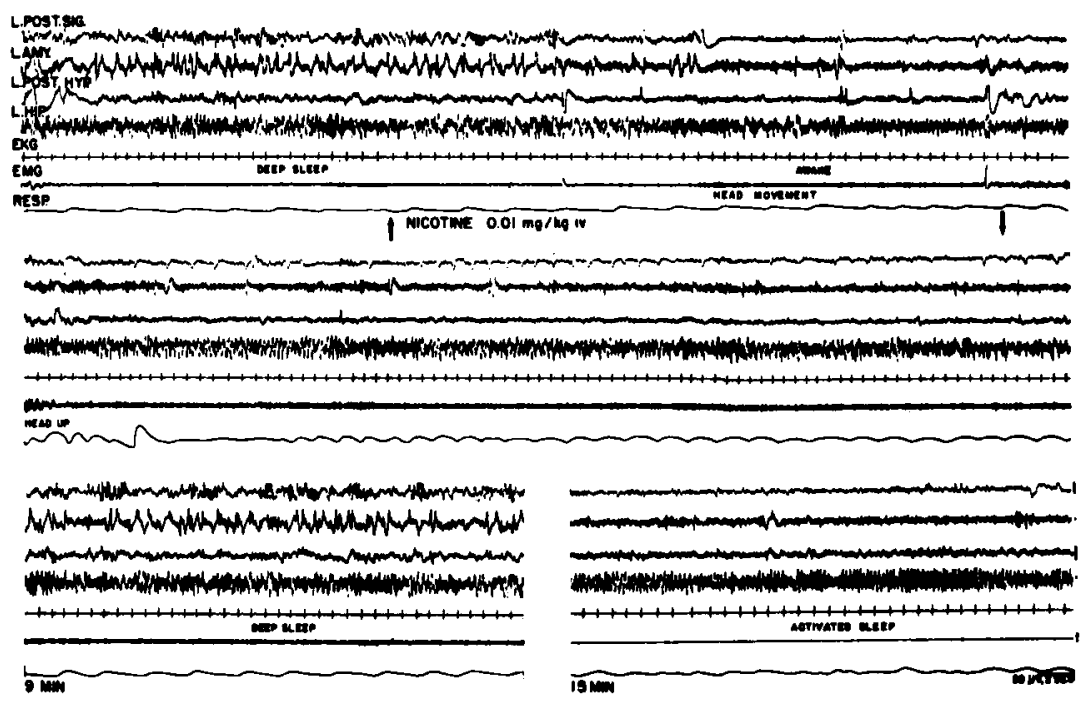

FIGURE 9. EEG Effects of Nicotine in the Cat with Chronically Indwelling Brain Electrodes. Nicotine $(10 \mu \mathrm{g} / \mathrm{kg})$ was given intravenously between the two arrows during slow-wave sleep. Note the changes in EEG activity and behavior. The upper two records are continuous; the lower are 9 and 15 minutes later. All recordings were bipolar. Symbols: L. POST. SIG. = left posterior sigmoid gyrus; L. AMY. = left amygdala; L. POST. HYP. = left post hypothalamus; L. HIP. = left hippocampus; EMG = electromyograph of neck muscles; RESP. = thoracic respiration. Voltage calibrations are as indicated.

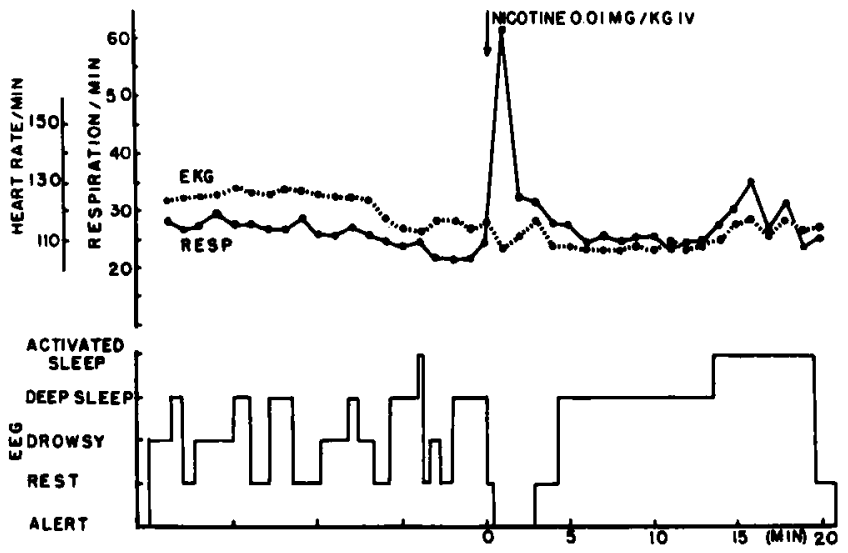

FIGURE 10. Effects of Nicotine in the Cat. The EEG stages and heart and respiration rates per minute are plotted for 20 minutes before and after intravenous nicotine. The data were obtained from the same cat whose EEG is shown in FIGURE 9. 


\section{Differential Receptors for EEG Activation and Behavioral Arousal for $\mathrm{n}$ and $\mathrm{m}$ Cholinergic Agonists}

The EEG and behavioral effects of nicotine in the intact animal could be due to a variety of phenomena. Even though it had been shown that the predominant site of action for EEG activation by nicotine in the acute brainstem-transected preparation was central, this remained to be proved in chronic experiments with intact cats. It was decided to study the effects of nicotine before and after the administration of various $n$ and $m$ cholinergic antagonists with predominantly peripheral and/or central actions. Two $m$ cholinergic antagonists were chosen: methylatropine, with predominantly peripheral actions; and atropine, with both peripheral and central actions. Two $n$ cholinergic ganglionic antagonists were also chosen: trimethidinium, with predominantly peripheral actions; and mecamylamine, with both peripheral and central actions. Since large doses of either atropine or mecamylamine interfered with the sleep cycle of the cat, doses of these compounds were kept small.

As can be seen in FIGURE 11, only mecamylamine completely prevented the EEG and behavioral arousal effects of nicotine. This is in marked contrast
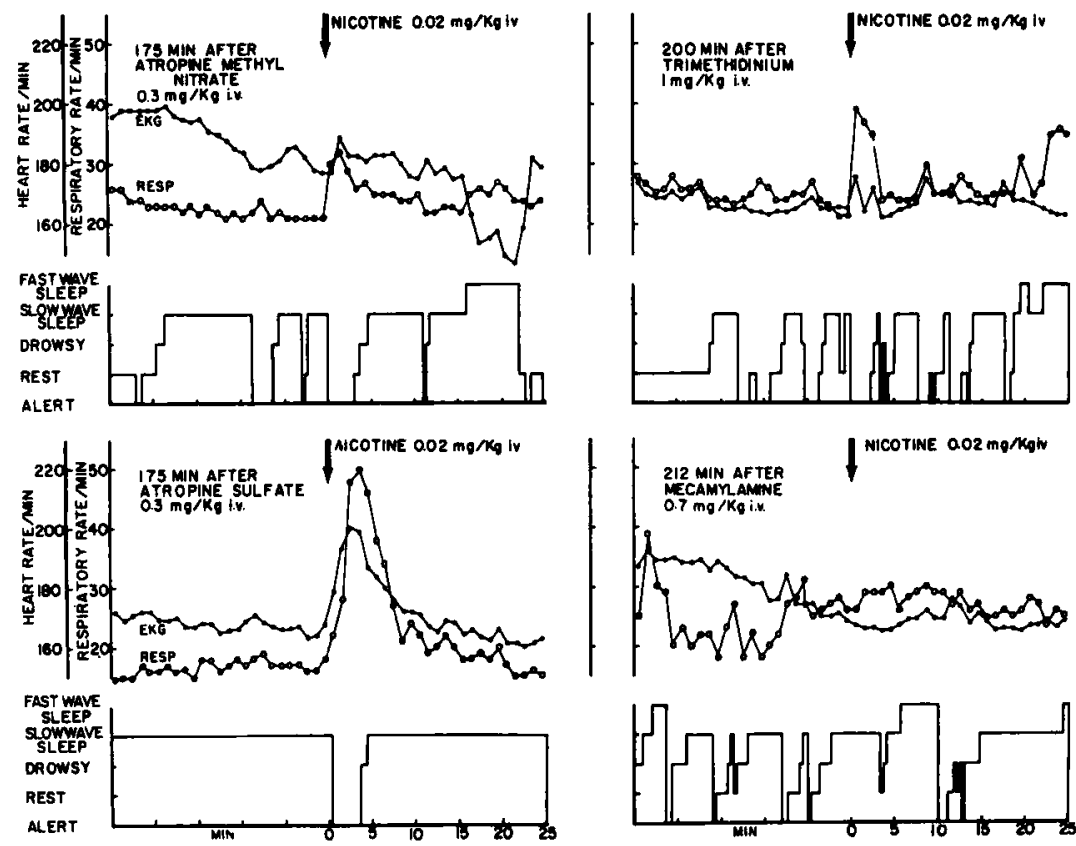

FIGURE 11. Modification of the Effects of Nicotine by Various $m$ and $n$ Cholinergic Antagonists in the Cat. The doses of various agents given intravenously are listed. Approximately 180 or more minutes elapsed after each pretreatment given on different days before nicotine was injected; this was to achieve stable conditions of sleep. Note that only after mecamylamine were the effects of nicotine abolished. 
to the EEG and behavioral arousal effects of arecoline, which were blocked only by atropine (see FIGURE 12). These data confirm the conclusions obtained in the acute experiments described above. Thus $m$ and $n$ cholinergic receptors in the brain are capable of producing EEG activation and behavioral arousal, and the effects of arecoline last longer and are more dramatic than those of nicotine.

Since cats with chronic indwelling brain electrodes vary widely in their patterns of arousal and sleep, it was felt necessary to quantitate the various stages of sleep for periods up to 25 minutes before and after the injection of nicotine and arecoline, in animals pretreated with various cholinergic antagonists. The data for all cats studied are summarized in bar graphs of each EEG stage as mean percentage \pm standard error (SE) (see FIGURES 13 and 14).

After the administration of saline, the cats showed varying percentages of the alert, resting, drowsy, slow-wave, and fast-wave sleep states. After an intravenous dose of $10 \mu \mathrm{g} / \mathrm{kg}$ of nicotine, the percentage of alertness increased. This was accompanied by a decrease in drowsiness and slow-wave sleep, and was followed by a definite increase in the percentage of fast-wave sleep.
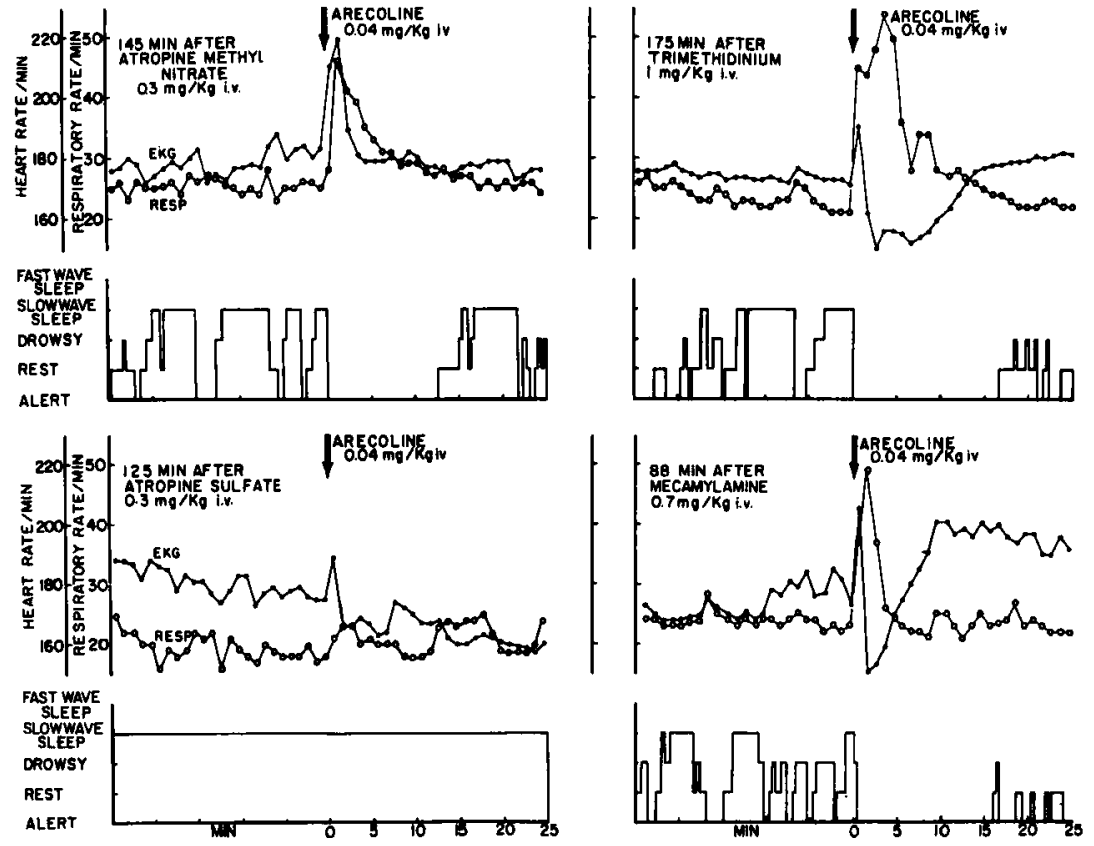

FIGURE 12. Modification of the Effects of Arecoline by Various $m$ and $n$ Cholinergic Antagonists in the Cat. The doses of various agents given intravenously are listed. No two pretreatments were given on any one day. When stable conditions for sleep were obtained, arecoline $(40 \mu \mathrm{g} / \mathrm{kg})$ was given. Note that only atropine abolished the effects of arecoline. Even large doses $(0.6 \mathrm{mg} / \mathrm{kg})$ of methylatropine did not block the EEG effects of arecoline. 


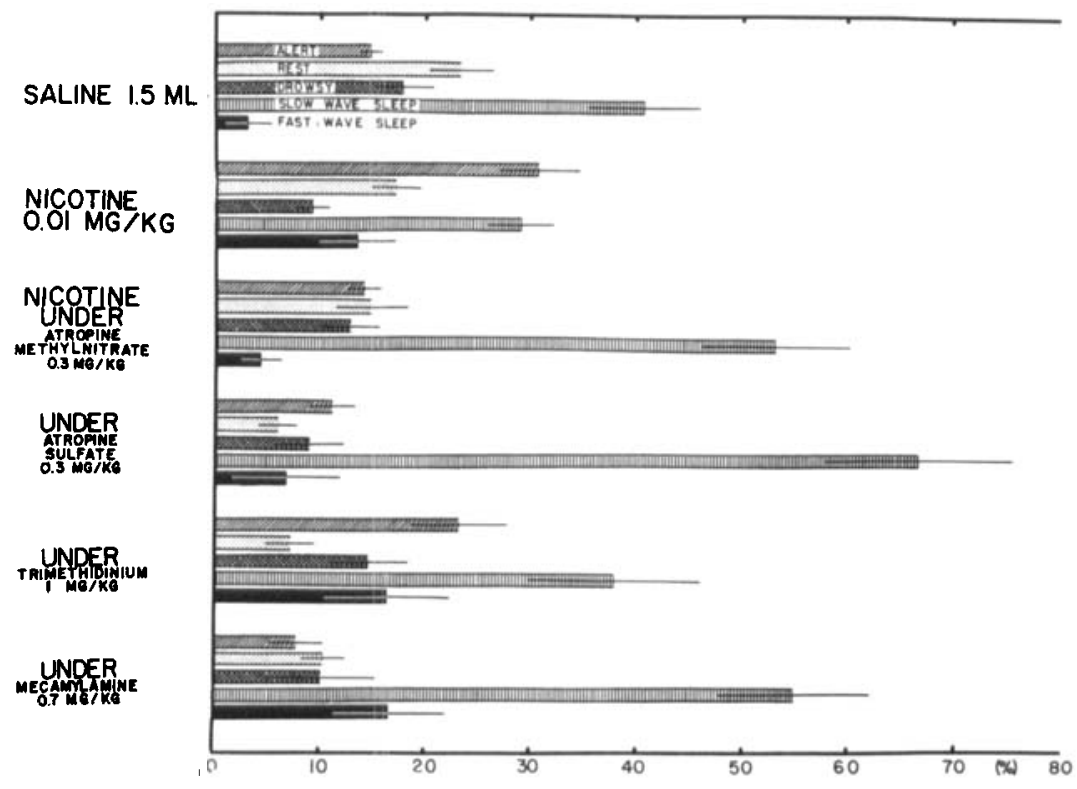

FIGURE 13. Mean Percentage of Each EEG State of Sleep 25 Minutes after Nicotine Injection following Pretreatment with Various $m$ and $n$ Cholinergic Antagonists. The graph summarizes the mean $\pm \mathrm{SE}$ of nine cats for each $E E G$ state after various pretreatments, as shown. Note that both atropine and, especially, mecamylamine block the increase in percentage of alert state after nicotine injection. Both methylatropine and trimethidinium reduced this percentage. Marked individual variability was observed, as the large SE's show.

Atropine blocked these effects of nicotine; the cat remained primarily in slow-wave sleep. Somewhat similar findings were noted after the administration of methylatropine. Trimethidinium reduced the altering effects of nicotine only slightly, but mecamylamine blocked them. In contrast with the effects of nicotine, arecoline produced a much longer duration of alerting but no significant increase in fast-wave sleep (see FIGURE 14). Atropine blocked completely the actions of arecoline, but methylatropine only reduced them. After either trimethidinium or mecamylamine, arecoline was even more effective in causing EEG and behavioral arousal. The significance of this finding is not known. It would appear that the same specificity of $m$ and $n$ cholinergic agonists and antagonists, as demonstrated in acute animals, applies to cats with chronically indwelling brain electrodes.

\section{Comparison of the Effects of Nicotine and Other Cardiovascular Drugs upon the EEG Stages of Sleep}

Since small doses of nicotine have marked cardiovascular effects, particularly in unanesthetized animals, it was of interest to determine the effects of other cardiovascular drugs upon the EEG. Therefore, nine cats were studied 


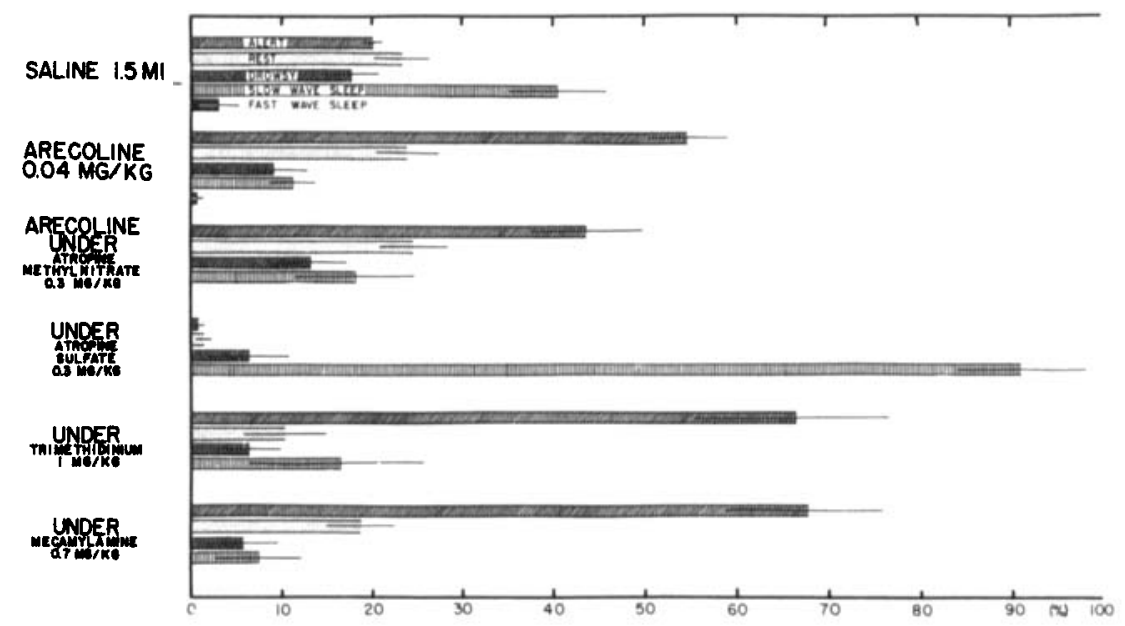

FIGURE 14. Mean Percentage of Each EEG State of Sleep 25 Minutes after Arecoline Injection following Pretreatment with Various $m$ and $n$ Cholinergic Antagonists. The graph is similar to that in FIGURE 13. Note that atropine was the only agent that completely blocked the effects of arecoline. After atropine alone, the animals showed a marked increase in slow-wave sleep.

before and after treatments with: saline, $1.5 \mathrm{ml}$; nicotine, $10 \mu \mathrm{g} / \mathrm{kg}$; epinephrine, $2 \mu \mathrm{g} / \mathrm{kg} ;$ DMPP, $5 \mu \mathrm{g} / \mathrm{kg}$; arginine vasopressin, $50 \mathrm{mPu} / \mathrm{kg}$; lysine vasopressin, $50 \mathrm{mPu} / \mathrm{kg}$; phenylalanine lysine vasopressin (PLV-2), $50 \mathrm{mPu} / \mathrm{kg}$; or angiotensin, $2 \mu \mathrm{g} / \mathrm{kg}$. Since the alerting effects of nicotine are relatively transient, the percentages of EEG levels 5 and 25 minutes before and after administration of these drugs were compared. A modified Latin square design was used in which the cats were tested at intervals of one to three days between drugs.

As FIGURE 15 shows, nicotine caused a marked increase in the mean percentage of EEG and behavioral arousal for a 5-minute period after injection. This effect was accompanied by a decrease in the amount of time spent in the drowsy state and in slow-wave sleep. Somewhat similar effects were produced by epinephrine, DMPP, the vasopressins, and angiotensin. From these findings, it is obvious that a large variety of cardiovascular agents can produce a brief wake-up effect, primarily by peripheral actions. Comparison of the percentage of EEG stages 25 minutes before and after the same drugs shows that the percentage of sleep after nicotine was not markedly altered, although the amount of fast-wave sleep increased (see FIGURE 16). It is interesting that epinephrine, DMPP, lysine vasopressin, and angiotensin did not significantly increase fast-wave sleep, although arginine vasopressin and, especially, PLV-2 were effective.

It can be concluded that nicotine, in doses of $10 \mu \mathrm{g} / \mathrm{kg}$, given over a one-minute period, produces transient behavioral arousal and EEG activation in cats with chronically indwelling brain electrodes. The effects of nicotine 


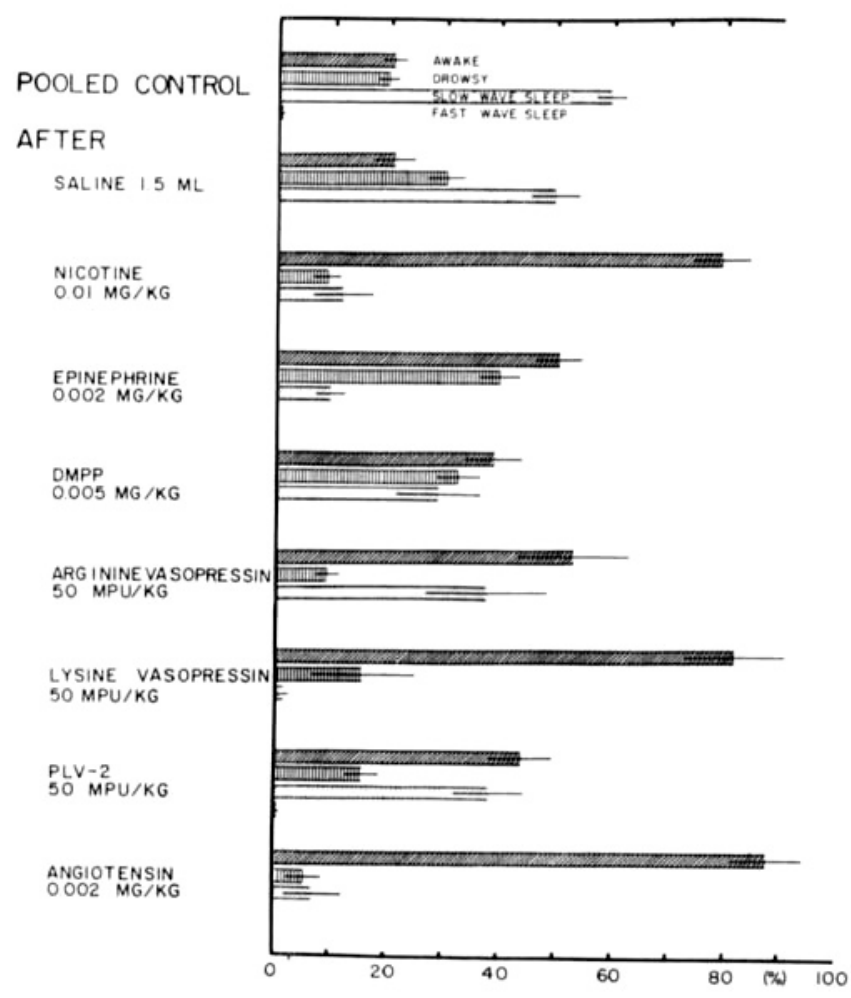

FIGURE 15. Mean Percentages of Time Spent by Cats in Different EEG States 5 Minutes before and after Various Pretreatments. The pooled control data before and after saline injection show similar trends. Note, however, that all the drugs increase the amount of time spent in alertness, reflecting peripheral afferent stimulation from rises in blood pressure, etc. This contributes to the wake-up effect in intact animals. All drugs were given over a one-minute period in the doses listed. The drugs were injected during slow-wave sleep. The data represent a mean $\pm \mathrm{SE}$ of 5-15 cats.

were evident chiefly when the animals were in natural slow-wave sleep, as observed behaviorally and by EEG recordings from various cortical and subcortical sites. After nicotine administration, the animals were aroused for a few minutes and later became behaviorally sleepy and showed EEG slow waves. This was frequently followed by fast-wave sleep. This latter effect of nicotine has also been observed by Jewett and Norton (1965).

Approximately equipressor doses of a variety of cardiovascular drugs produce similar EEG activation and behavioral arousal phenomena. Obviously, in an intact animal given nicotine, the release of various neurohumors, such as vasopressin and epinephrine, contributes to the EEG activation and behavioral arousal effects. As noted previously, pretreatment with trimethidinium $(2 \mathrm{mg} / \mathrm{kg}$ ) prevented the cardiovascular effects of nicotine and reduced, but did not block, the behavioral arousal and EEG activating actions. 


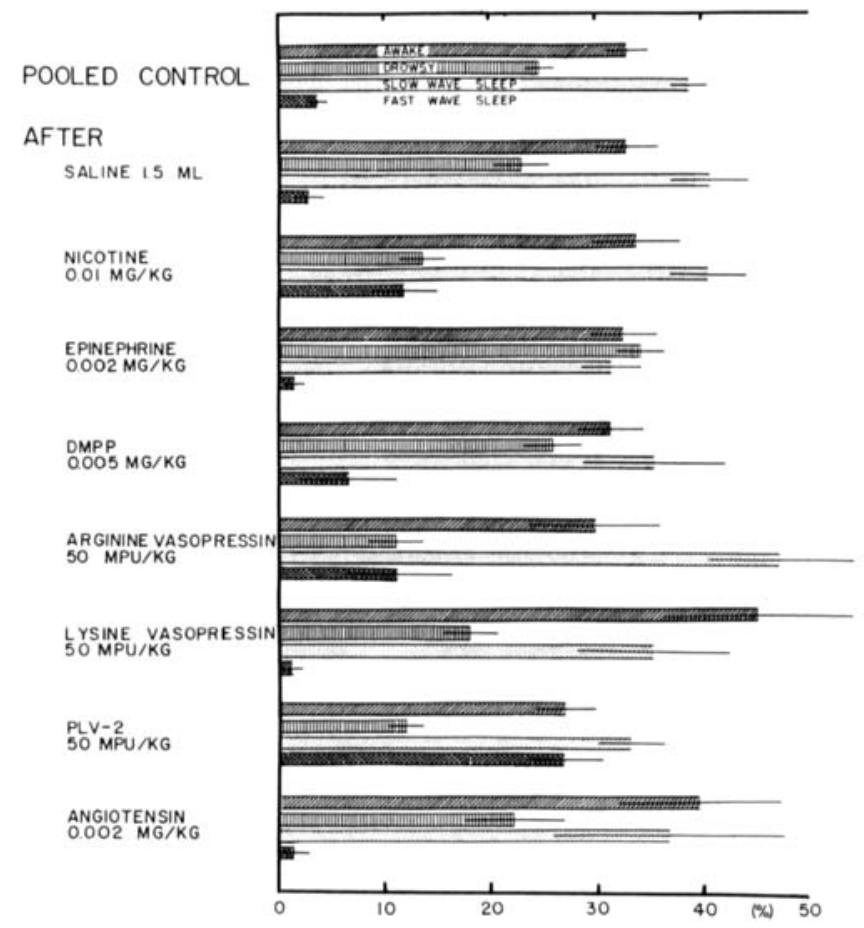

FIGURE 16. Mean Percentage of Time Spent by Cats in Different EEG States 25 Minutes before and after Various Pretreatments. The data from the same experiments as in FIGURE 15 are plotted for a 25-minute period to illustrate especially the changes in fast-wave sleep. Note that only nicotine and the vasopressins increased the percentages of fast-wave sleep. PVL-2 and arginine vasopressin were much more effective than lysine vasopressin in equal millipressor units. These compounds were kindly provided by Sandoz Pharmaceuticals.

By such pharmacological techniques, it can be concluded that the behavioral arousal and EEG desynchronizing effects of nicotine are due primarily to an action on the central nervous system; but, as might well be expected, the release of various neurohormones or stimulation of the peripheral afferents contributes to the total phenomenon seen in intact animals.

\section{Failure of Small Doses of Nicotine Given at Bedtime to Alter the Sleep Cycle of Normal Human Volunteers}

In view of the fact that nicotine and vasopressin transiently increase the amount of wakefulness and fast-wave sleep in the cat, it was thought to be important to determine whether these findings apply to man (Varma \& Domino, 1966). Eight normal male university students were selected for subjects on the basis of (a) signed written consents; (b) no evidence of psychosis, organicity, convulsive disorders, etc.; (c) between 18 and 30 years of age; (d) were normal from the point of view of history and physical 
examination, including a diagnostic EEG; and (e) had no medication for at least one month before the study. Light smokers (less than one pack a day) and nonsmokers participated. The subjects took no alcohol or cigarettes after 6:00 p.m. on the evening of the study. They were unaware of the medications they were receiving.

Drug dosage, given intramuscularly, was as follows: nicotine tartrate, $15 \mu \mathrm{g} / \mathrm{kg}$; lysine vasopressin or phenylalanine lysine vasopressin, (PLV-2) $50 \mathrm{mPu} / \mathrm{kg}$; or $2.0 \mathrm{ml}$ of physiological saline. The subjects had at least one night of habituation, with the electrodes applied, before actual trials. Medication was administered at the hour of sleep (10:00-10:30 p.m.). Each subject then slept continuously for at least seven hours. Recordings were made throughout the night. They included monopolar EEGs to both ears (as reference), the electro-oculogram (EOG) from left to right eye, and EKG lead II. The polygraph records were analyzed according to Dement and Kleitman's (1957) classification of sleep, as modified by Williams et al. (1964).

It was noted that physiological saline affected significantly the sleep cycle of normal volunteers (see TABLE 2). The percentage of fast-wave sleep (Stage I) increased from a mean $€ \mathrm{SE}$ of $20.9 \pm 2.2$ to $25.7 \pm 2.5$ after saline. The intramuscular administration of nicotine frequently caused a stinging sensation at the site of injection. Within one minute, some of the subjects

TABLE 2

LACK OF SIGNIFICANT EFFECTS OF NICOTINE AND VASOPRESSIN UPON THE EEG STAGES OF SLEEP IN NORMAL HUMAN VOLUNTEERS*

\begin{tabular}{l|c|c|c|c|c|c}
\hline \multirow{2}{*}{ Treatment } & \multirow{2}{*}{$\mathrm{N}$} & \multicolumn{5}{|c}{ Mean percent \pm SE for each EEG stage } \\
\cline { 3 - 7 } & & Drowsy & $\mathrm{I}$ & $\mathrm{I}$ & $\mathrm{II}$ & $\mathrm{IV}$ \\
\hline $\begin{array}{l}\text { No medication } \\
\text { Saline }\end{array}$ & 8 & $3.5 \pm 1.3$ & $20.9 \pm 2.2$ & $35.4 \pm 5.1$ & $17.1 \pm 3.7$ & $22.5 \pm 1.7$ \\
\hline $\begin{array}{l}\text { Nicotine } \\
15 \mu \mathrm{g} / \mathrm{kg}\end{array}$ & 7 & $1.9 \pm 0.5$ & $25.7 \pm 2.5 \dagger$ & $28.5 \pm 2.9$ & $20.9 \pm 2.4$ & $23.0 \pm 2.8$ \\
\hline $\begin{array}{l}\text { Lysine } \\
\text { vasopressin } \\
50 \mathrm{mU} / \mathrm{kg}\end{array}$ & 8 & $1.0 \pm 0.2$ & $28.6 \pm 3.0 \dagger$ & $36.4 \pm 2.9$ & $15.1 \pm 1.9$ & $18.8 \pm 3.6$ \\
\hline $\begin{array}{l}\mathrm{PLV}-2 \\
50 \mathrm{mU} / \mathrm{kg}\end{array}$ & 8 & $1.2 \pm 0.3$ & $24.9 \pm 1.6$ & $28.1 \pm 2.1$ & $25.7 \pm 3.3 \dagger$ & $20.1 \pm 2.5$ \\
\hline
\end{tabular}

*All injections were given intramuscularly.

$\nmid$ Differs significantly from No medication. Paired comparison, Student " $t$," $\mathbf{P}<.05$. 
felt "dizzy," "light-headed," and nauseated. This feeling seldom lasted more than 5 minutes. Usually, the subjects fell asleep about the same time as after the saline injection and showed no striking alteration in their sleep behavior. Immediately after the injections of nicotine, the heart rates increased slightly.

Lysine vasopressin and, especially PLV-2, in doses of $50 \mathrm{mPu} / \mathrm{kg}$, occasionally caused a decrease in heart rate which lasted less than one hour. During this time, some subjects complained of a slight uneasiness and the feeling of having to move their bowels. These were not prominent symptoms, and the subjects usually fell asleep promptly. In comparison to no medication, lysine vasopressin increased significantly the percentage of Stage I, from a mean $\pm \mathrm{SE}$ of $20.9 \pm 2.2$ to $28.6 \pm 3.0$. PLV -2 also increased significantly the amount of Stage III. Lysine vasopressin was more effective than PLV-2 in shortening the time between the injection and the onset of Stage I.

In this very preliminary study, six of the eight subjects were nonsmokers and the other two were light smokers, averaging less than 1 pack of cigarettes per day. No differences between light smokers and nonsmokers were observed in onset, duration, pattern of sleep, or responses to nicotine. One can conclude that under the conditions of this study, in which nicotine was given at bedtime, no evidence of a wake-up effect or facilitation of Stage I sleep was obtained. The reason may be that the action of nicotine is relatively short, so that the compound could hardly be expected to alter a sleep cycle 7-8 hours long. The vasopressins also had no significant effects upon the sleep cycle under these circumstances. However, this needs to be studied further.

\section{Behavioral Actions of Nicotine in the Rat \\ Differential Effects upon Latency of Avoidance in "Slow" vs. "Fast" Rats}

There have been many studies of the behavioral effects of nicotine in animals and man (see Silvette et al., 1962). One can summarize the literature by saying that nicotine has little to no effect, and that when it does act, it is either a stimulant or a depressant according to dose, duration of treatment, behavioral task, and species. Our interest in the behavioral effects of nicotine developed from a desire to understand the significance of the EEG activation it induces. As already noted, the EEG actions are rather transient. Nevertheless, in cats, they are associated with behavioral arousal and are followed by an increase in fast-wave sleep. It can be predicted that this brief wake-up effect observed in the EEG can be shown to have behavioral correlates under the proper experimental circumstances.

It has been previously reported (Domino, 1965a) that nicotine in large doses has marked effects upon conditioned avoidance behavior in the rat. The action of large doses of nicotine upon established conditioned pole-jumping behavior is reminiscent of the effects of chlorpromazine. These actions are produced by relatively large doses of nicotine and therefore are probably 
unrelated to the effects of the small doses absorbed during tobacco smoking. In our experiments, nicotine has shown no consistent effect upon the acquisition of conditioned avoidance behavior. It has been possible upon occasions to show that nicotine, in small doses, facilitates acquisition and delays extinction, but that large doses have reproducibile depressant actions. We reported these findings at the Tobacco Symposium in Stockholm (Domino, 1965a). At that time, Bovet (1965) and Bovet-Nitti (1965) pointed out that small doses of nicotine have facilitating effects upon behavior, especially in the naive rat. These effects were considered to be similar to those of amphetamine, and different from those of chlorpromazine and other related drugs. The Bovets emphasized some very important facts: It was necessary to use split-litter techniques to reduce variability. Furthermore, by using separate "bright" and "dull" groups of rats, they were able to demonstrate the facilitating effects of nicotine, especially in slow learners. Our own data have indicated that the EEG-activating actions of nicotine, or its behavioral wakeup effect in chronic cats, appeared only when the dose was administered during a state of mild central nervous system depression or sleep. This suggests that nicotine should have an alerting effect upon behavior only in fatigue states or other states of slight central nervous system depression. The degree of depression must be slight, however; because barbiturates, even in small doses, easily block nicotine's EEG activating effects.

We have previously reported that small doses of nicotine have no consistent effect upon the response latency for conditioned avoidance behavior in monkeys (Domino, 1965a). On the other hand, Bovet-Nitti (1965) has been able to show a reduction in reaction times following nicotine. We have reexamined this problem from the point of view of the effect of nicotine in animals with "fast" vs. "slow" latency times for conditioned avoidance pole jumping. In a modification of the original Cook and Weidley (1957) technique, rats were trained to react to a buzzer stimulus to avoid an electric shock applied to the grid floor. A 5-second buzzer tone was the conditioned stimulus (CS), and a 5-second, 1 milliampere, $60 \mathrm{cps}$ electroshock was the unconditioned stimulus (US); these were used under overlap conditions. Male Holtzman rats of 200-500 gm were employed. The rats were trained in blocks of 20 trials to a total of 200 trials for a $90 \%$ avoidance criterion. Animals not reaching this criterion were discarded.

On the day of testing, the trained rats were given 20 control trials and 60 postdrug trials. Within each block of 20 trials, there were random intertrial intervals with a mean duration of 45 seconds; the interval between blocks was three minutes. Latency of avoidance and escape were measured automatically. Nicotine was given in doses of 40,80 , and $160 \mu \mathrm{g} / \mathrm{kg}$ as base, subcutaneously. Physiological saline was given in comparable volumes, which did not exceed $0.5 \mathrm{ml}$. After the 20 control trials, the drug was injected; then, after a one-minute wait, the postdrug trials began. The mean avoidance latency $\pm \mathrm{SE}$ for saline and for increasing doses of nicotine, for groups of six 
or more rats selected at random, are shown in FIGURE 17. It can be seen that after saline and $40 \mu \mathrm{g} / \mathrm{kg}$ of nicotine, there was a tendency for the mean avoidance latency to increase with the number of trial blocks. This trend was reversed after the administration of 80 and $160 \mu \mathrm{g} / \mathrm{kg}$ of nicotine, especially for postnicotine trials 1-20 and 21-40. A dose of $40 \mu \mathrm{g} / \mathrm{kg}$ of nicotine was not significantly different from saline in altering the percentage of avoidance behavior in postinjection trials $1-20$. However, $80 \mu \mathrm{g} / \mathrm{kg}$ caused a $1.3 \%$ reduction of avoidance behavior, and $160 \mu \mathrm{g} / \mathrm{kg}$ caused a $4 \%$ reduction. Therefore, another experiment was run in which 12 trained rats were given 20 control trials, followed by saline injection and one US. Then the normal CS-US sequence was run in blocks of 20 trials. This experiment mimicked the actions of nicotine by causing an automatic 5\% increase in the number of escape responses. Under these circumstances the mean avoidance latency ${ }_{\mathrm{S}} \mathrm{SE}$ was $1.59 \pm 0.12$ before injection, and $1.41 \pm 0.16$ for post-injection trials $1-20,1.65 \pm 0.19$ for trials $21-40$, and $1.79 \pm 0.16$ for trials $41-60$. These effects with saline plus electroshock are almost identical with those obtained after nicotine (see FIGURE 18). The slight increase in the number of escape

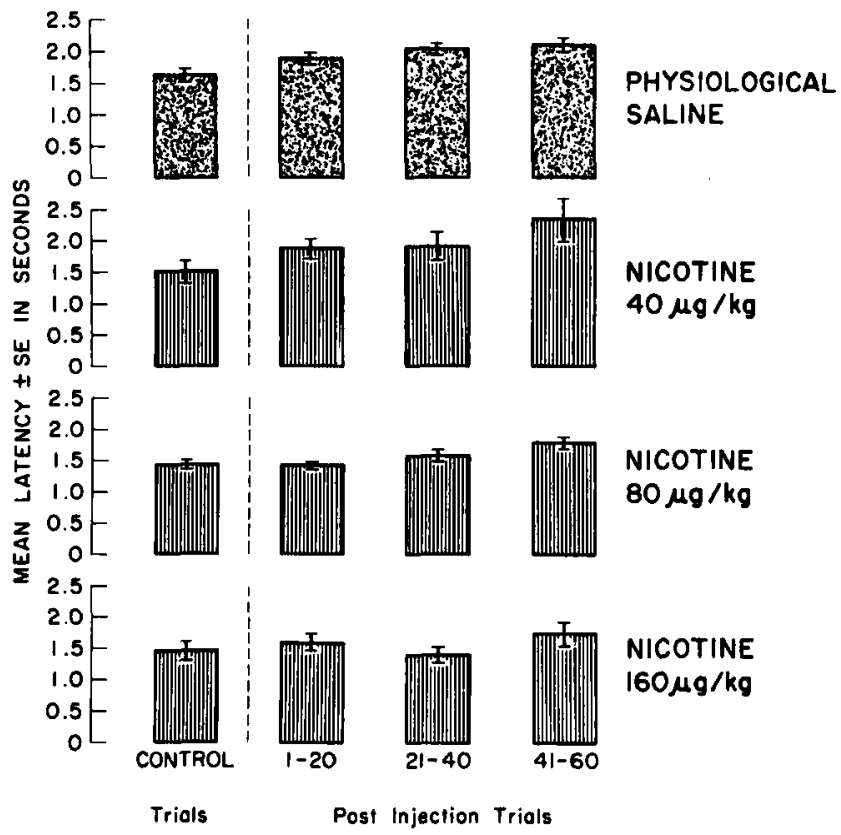

FIGURE 17. Effects of Increasing Doses of Nicotine upon Mean Avoidance Latency for Pole Jumping in Trained Rats. The mean latencies $\pm \mathrm{SE}$, in seconds, of groups of 6 or more rats given either saline or various doses of nicotine subcutaneously are shown. The mean latencies of 20 control trials before injection are followed by the mean latencies of postinjection blocks of 20 trials each. Note that latencies for saline and for $40 \mu \mathrm{g} / \mathrm{kg}$ of nicotine increased with each block of trials. On the other hand, 80 and $160 \mu \mathrm{g} / \mathrm{kg}$ of nicotine temporarily reverse this trend for the first and second postinjection blocks. 


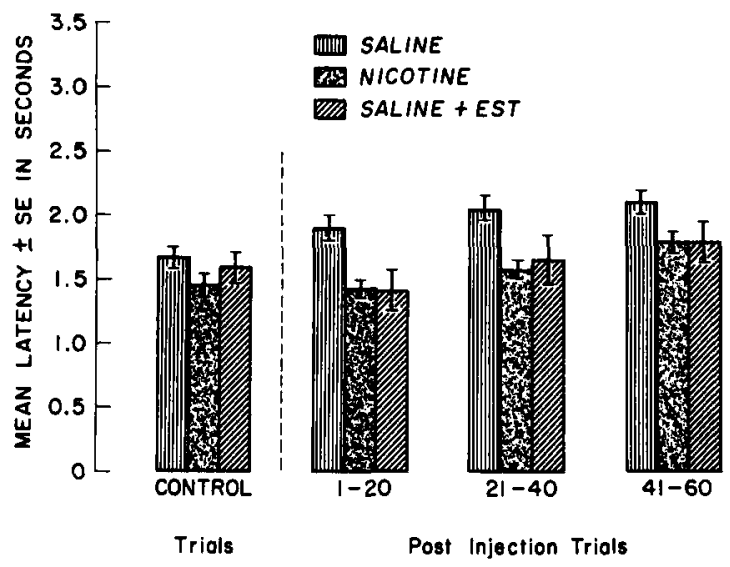

FIGURE 18. Similarity of Effect of Saline plus Electroshock to that of Nicotine upon Mean Avoidance Latencies for Conditioned Pole Jumping in Rats. After saline injection and one unconditioned stimulus, the subsequent mean avoidance latencies were decreased to the same extent as after nicotine.

responses due to exposure to electroshock after nicotine might account for the decrease in latency, since one postsaline US speeds up subsequent avoidance responses.

A dose of $80 \mu \mathrm{g} / \mathrm{kg}$ of nicotine produced much less depression of avoidance behavior and an even greater decrease in mean avoidance latency than $160 \mu \mathrm{g} / \mathrm{kg}$ of nicotine. It seemed that the speed-up effect of nicotine was not associated only with its ability to decrease conditioned avoidance behavior and thus increase the motivation of the rats due to exposure to electroshock during the US interval. A large number (30) of trained rats were given $80 \mu \mathrm{g} / \mathrm{kg}$ of nicotine each and tested for the latency of pole jump avoidance as described above. The animals were divided into two groups, one "fast" and the other "slow," on the basis of their control avoidance latencies. The differential effects of saline and nicotine are graphed in FIGURE 19. Saline and nicotine caused the same prolongation of mean avoidance latency in the "fast" rats. The nicotine-treated rats tended to be slightly faster, but the standard errors overlapped with those for saline except for postinjection trials 41-60. On the other hand, the "slow" rats given nicotine showed a definite decrease in mean latency compared to those given saline, especially in postinjection trials $1-20$ and $21-40$. This decrease was statistically significant $(P<0.05)$. Nicotine reduced avoidance behavior in both groups during postinjection trials 1-20 (see FIGURE 20 ), by $3.7 \%$ for the "fast" group and $5.7 \%$ for the "slow" group. Is it possible that this $2 \%$ difference in exposure to electroshock can account for such dramatic differences? Since electroshock is an effective motivator, one would be inclined to answer yes, although further work must obviously be done to prove this. It should be noted that during postinjection trials 21-40 there was no reduction of avoidance behavior 


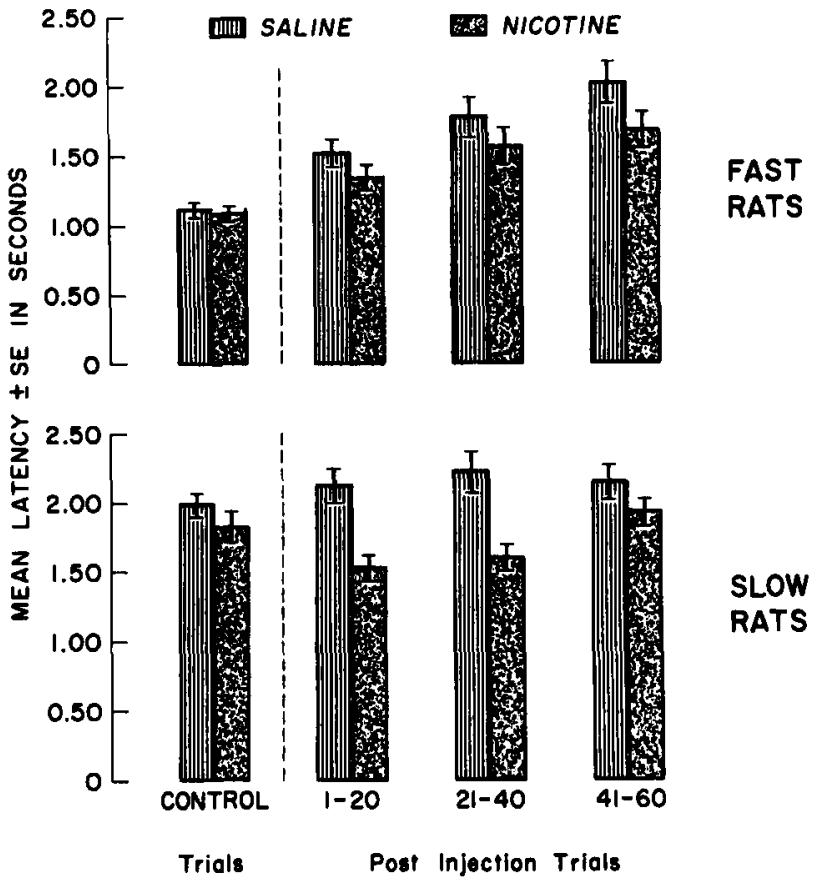

FIGURE 19. Differential Effects of Nicotine upon the Mean Avoidance Latencies for Pole Jumping in "Fast" vs. "Slow" Rats. The mean latencies $\pm \mathrm{SE}$ in seconds of groups of 15 or more rats given saline or nicotine in a subcutaneous dose of $80 \mu \mathrm{g} / \mathrm{kg}$ are shown. "Fast" rats, whether treated with saline or with nicotine show similar trends for slower mean avoidance latencies after injection. The "slow" rats treated with saline show a similar trend. However, "slow" rats treated with $80 \mu \mathrm{g} / \mathrm{kg}$ of nicotine show a temporary speed-up for the first and second postinjection trial blocks.

in either group, yet the mean avoidance latency of the slow rats was still less than that of the saline-treated "slow," or saline- or nicotine-treated "fast" rats. However, similar effects were noted with saline plus electroshock.

\section{SUMMARY}

There are two different reasons for interest in the actions of nicotine on the central nervous system. One is related to the presence of nicotine in tobacco, possibly serving as a reinforcer of the habit of smoking tobacco. The other is the use of nicotine to increase the understanding of cerebral cholinergic mechanisms. These two interests are quite compatible, particularly if small doses of nicotine are used. For the past six years, research in our laboratory has been directed toward elaborating the central actions of nicotine. To date, we can say something about the actions of small doses of nicotine upon the central nervous system and central cholinergic mechanisms. Their relationship to tobacco smoking is still unknown, but the fact that very small doses of nicotine cause rather clear-cut central actions suggests that any theory of the 


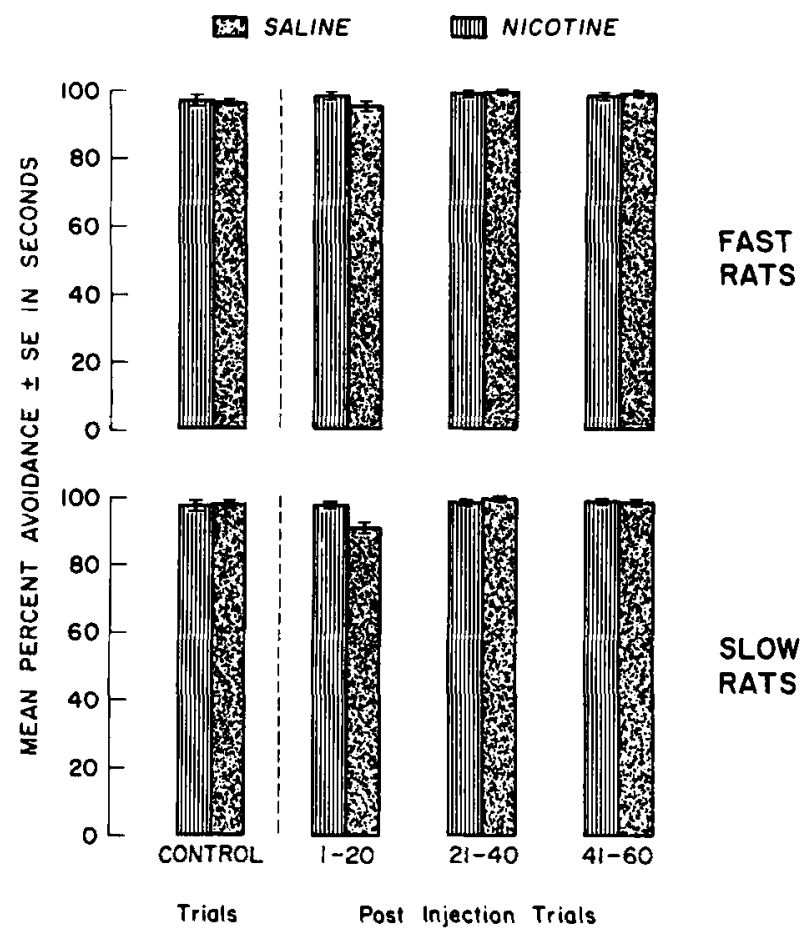

FIGURE 20. Differential Effects of Nicotine upon Mean Percentage of Avoidance Response in "Fast" and "Slow" Rats. The mean $\mathrm{SE}$ percentage of avoidance responses for pole jumping are plotted. Note that nicotine at $80 \mu \mathrm{g} / \mathrm{kg}$ depressed avoidance behavior in the "slow" rats slightly more than in the "fast" ones. Thus, the findings given in FIGURE 19 may be related to the number of electroshocks obtained from failure to avoid when under the influence of nicotine.

cause or maintenance of tobacco smoking must take into account these pharmacological facts.

If one were arbitrarily choosing a drug for studying its possible actions on the central nervous system, perhaps no poorer choice could be made than nicotine. This agent has so many pharmacological actions that they easily confound, reinforce, and obscure its direct central actions. As an $n$ cholinergic agonist, nicotine acts at a variety of sites in the peripheral nervous system. These multiple actions must be considered in any study of nicotine's effects upon the central nervous system.

We have used a neuro- and psychopharmacologic approach to determine the central actions of nicotine. Since nicotine releases acetylcholine, catecholamines, serotonin, and vasopressin, these compounds were studied as well. The effects of nicotine and related drugs upon the EEGs of acute and chronic animals were determined. In addition, the effects of nicotine upon gross and conditioned avoidance behavior were studied to provide behavioral correlates of the EEG changes. 
Nicotine, in doses of 5-20 $\mu \mathrm{g} / \mathrm{kg}$ i.v., causes EEG activation in acute experiments which is related to a behavioral wake-up effect. This action, which lasts only a few minutes, involves both central and peripheral components. Nicotine also causes an increase in fast-wave sleep, which may be related to vasopressin release. The initial behavioral consequences of small doses of nicotine are consistent with a brief wake-up effect.

In rats trained to pole jump, nicotine in subcutaneous doses of 80 and $160 \mu \mathrm{g} / \mathrm{kg}$ produced a transient decrease in mean avoidance latency within one or two minutes. In contrast, saline or $40 \mu \mathrm{g} / \mathrm{kg}$ of nicotine, produced a slight increase in avoidance latency. Mean avoidance latency decreased more in "slow" rats than in "fast" ones. The effects of nicotine were highly significant; the role of slightly increased percentages of unconditioned stimuli (electroshock) in increasing motivation in the nicotine-treated animals needs to be studied further.

In conclusion, the research reported here indicates that nicotine, in doses comparable to those absorbed by a man smoking tobacco, has pharmacological actions consistent with a brief wake-up effect as well as a transient period of mild central nervous system depression. The behavior depressant effects of nicotine are more evident with larger doses.

\section{Acknowledgments}

The author would like to acknowledge the collaboration of his former students and associates Drs. Dren, Knapp, Varma, Villarreal, and Yamamoto, as well as Mary Corcoran, Diana Fitzgerald, Myron Newton, and Jack Stawiski in completing various portions of this research.

\section{References}

BARLOW, R. B. 1965. Chemical structure and biological activity of nicotine and related compounds. In Tobacco Alkaloids and Related Compounds. U. S. von Euler, Ed. : 277-301. Pergamon Press. Oxford.

BARLOW, R. B. \& J. T. HAMILTON. 1962. Effects of $\mathrm{pH}$ on the activity of nicotine and nicotine monomethiodide on the rat diaphragm preparation. Brit. J. Pharmacol. 18: $543-549$.

BONVALLET, M., P. DELL \& G. HIEBEL. 1954. Tonus sympathique et activité électrique corticale. Electroenceph. Clin. Neurophysiol. 6: 119-144.

BOVET, D. 1965. Action of nicotine on conditioned behaviour in naive and pretrained rats. In Tobacco Alkaloids and Related Compounds. U. S. von Euler, Ed. : 126136. Pergamon Press. Oxford.

BOVET-NITTI, F. 1965. Action of nicotine on conditioned behaviour in naive and pretrained rats. II: Complex forms of acquired behaviour-discussion. In Tobacco Alkaloids and Related Compounds. U. S. von Euler, Ed. : 137-143. Pergamon Press. Oxford.

BRemer, F. 1953. Some Problems in Neurophysiology. : 31. Athlone Press. London. COOK, L. \& E. WEIDLEY. 1957. Behavioral effects of some psychopharmacological agents. Ann. N. Y. Acad. Sci. 66: 740-752. 
DEMENT, w. 1958. The occurrence of low voltage, fast electroencephalogram patterns during behavioral sleep in the cat. Electroenceph. Clin. Neurophysiol. 10: 291-296.

DEMENT, W. \& N. KLEITMAN. 1957. Cyclic variations of EEG during sleep and their relation to eye movements, body motility and dreaming. Electroenceph. Clin. Neurophysiol. 9: 673-690.

DENISENKO, P. O. 1962. Influence of pharmacological agents upon cholinoreactive and adrenoreactive systems of the reticular formation and other regions of the brain. First Internat. Pharmacol. Meeting, Pharmacological Analysis of Central Nervous Action. W. D. M. Paton, Ed. 8: 199-209. Macmillan. New York.

DOMINo, E. F. 1965a. Some behavioral actions of nicotine. In Tobacco Alkaloids and Related Compounds. U. S. von Euler, Ed. : 145-166. Pergamon Press. Oxford.

DOMINO, E. F. 1965b. Some comparative pharmacological actions of $(-)$ nicotine, its optical isomer, and related compounds. In Tobacco Alkaloids and Related Compounds. U. S. von Euler, Ed. : 303-313. Pergamon Press. Oxford.

DOMINO, E. F., A. T. DREN \& K. YAMAMOTO. 1966. Pharmacologic evidence for cholinergic mechanisms in neocortical and limbic activating systems. Symposium on Limbic System Progress in Brain Research, Hakone, Japan (September 1965). To be published.

DOMINO, E. F. \& K. YAMAMOTO, 1965. Nicotine: Effect on the sleep cycle of the cat. Science. 150: 637-638.

DREN, A. T. \& E. F. DOMINO. 1965. Some effects of hemicholinium (HC-3) on EEG desynchronization mechanisms in the dog. Pharmacologist. 7: 153.

DUNLOP, C. W., C. STUMPF, D. S. MAXWELL \& W. SCHINDLER. 1960. Modification of cortical, reticular and hippocampal unit activity by nicotine in the rabbit. Amer. J. Physiol. 198: 515-518.

FLORIS, V., G. MOROCUTTI \& G. F. AYALA. 1962. Azione della nicotina sulla attivitá bioelectrica della corteccia del talamo e dell' ippocampo nel coniglio. Sua azione di "arousal" e convulsivante primitiva sulle strutture ippocampotalamiche. Boll. Soc. Ital. Biol. Sper. 38: 407-410.

ILYUTCHENOK, R. I. 1962. The role of cholinergic systems of the brainstem reticular formation in the mechanism of central effects of anticholinesterase and cholinolytic drugs. First. Internat. Pharmacol. Meeting, Pharmacological Analysis of Central Nervous Action. W. D. M. Paton, Ed. 8: 211-216. Macmillan. New York.

JEWETT, R. E. \& S. NORTON. 1966. Effects of some stimulant and depressant drugs on the sleep cycle of cats. Exper. Neurol. 15: 463-474.

JOUVET, M. 1961. Telencephalic and rhombencephalic sleep in the cat. In Ciba Foundation Symposium on the Nature of Sleep. G. E. W. Wolstenholme and M. O'Connor, Eds. : 188-206. Little, Brown and Co. Boston.

KNAPP, D. E. \& E. F. DOMINO. 1962. Action of nicotine on the ascending reticular activating system. Int. J. Neuropharmacol. 1: 333-351.

KNAPP, D. E. \& E. F. DOMINO. 1963. Species differences in the EEG response to epinephrine, 5-hydroxytryptamine and nicotine in brainstem transected animals. Int. J. Neuropharmacol. 2: 51-55.

LONGO, V. G. 1962. Rabbit Brain Research. II: Electroencephalographic Atlas for Pharmacological Research. Effect of Drugs on the Electrical Activity of the Rabbit Brain. Elsevier Publishing Co. Amsterdam.

LONGO, V. G., G. P. von BERGER \& D. BOVET. 1954. Action of nicotine and of the "ganglioplégiques centraux" on the electrical activity of the brain. J. Pharmacol. Exp. Therap. 111: 349-359.

MICHELSON, M. J. 1961. Pharmacological evidence of the role of acetylcholine in the higher nervous activity of man and animals. Activ. Nerv. Super. 3: 140-147.

SCHMITERLÖW, C. G. \& E. HANSSON. 1965. Tissue distribution of $\mathrm{C}^{14}$-nicotine. In Tobacco Alkaloids and Related Compounds. U. S. von Euler, Ed. : 75-86. Pergamon Press. Oxford.

SILVESTRINI, B. 1958. Neuropharmacological study of the central effects of benactyzine and hydroxyzine. Arch. Int. Pharmacodyn. 116: 71-85.

SILVETTE, H., E. C. HOFF, P. S. LARSON \& H. B. HAAG. 1962. The actions of nicotine on central nervous system functions. Pharmacol. Rev. 14: 137-173. 
STERMAN, M. B., T. KNAUSS, D. LEHMANN \& C. D. CLEMENTE. 1965. Circadian sleep and waking patterns in the laboratory cat. Electroenceph. Clin. Neurophysiol. 19: 508-517.

STONE, C. A., M. L. TORCHIANA, A. NAVARRO \& K. H. BEYER. 1956. Ganglionic blocking properties of 3-methyl-amino-isocamphone hydrochloride (mecamylamine): a secondary amine. J. Pharmacol. Exp. Therap. 117: 169-183.

STUMPF, C. 1959. Die Wirkung von Nicotine auf die Hippocampusstatigkeit den Kaninchens. Arch. Exp. Path. Pharmak. 235: 421-436.

VARMA, U. K. \& E.F. DOMINO. 1966. Unpublished observations.

VILLARREAL, J. E. \& E. F. DOMINO. 1964. Evidence for two types of cholinergic receptors involved in EEG desynchronization. Pharmacologist. 6: 192.

WILLIAMS, R. L., H. W. AGNEW, JR. \& W. B. WEBB. 1964. Sleep patterns in young adults: an EEG study. Electroenceph. Clin. Neurophysiol. 17: 376-381.

YAMAMOTO, K. 1959. Studies on the normal EEG of the cat: comparison between the EEG of fixed cats and unfixed cats seen from the skull and subcortical leads in various consciousness levels and the corresponding behavior. Ann. Reports, Shionogi Research Laboratory. Osaka, Japan. 9: 1125-1164.

YAMAMOTO, K. \& E. F. DOMINO. 1965. Nicotine-induced EEG and behavioral arousal. Int. J. Neuropharmacol. 4: 359-373.

YAMAMOTO, K. \& E. F. DOMINO. 1966. Cholinergic agonist-antagonist interactions on neocortical and hippocampal EEG activation. Int. J. Neuropharmacol. Submitted for publication.

YAMAMOTO, K. \& R. KIDO. 1962. Neurophysiological studies on the nature of sleepneural mechanisms related to "activated sleep." Seishin-igaku. Tokyo. Japan. 11: 821-830. 